\title{
Effects of the competitive NMDA antagonist CPP on performance of a place and cue radial maze task
}

\author{
GREGORY L. LYFORD and LEONARD E. JARRARD \\ Washington and Lee University, Lexington, Virginia
}

\begin{abstract}
Using a within-subjects design, rats were trained to run on a radial maze with a procedure that involved two types of learning (place and cue) and two memory functions (working and reference memory). After performance had stabilized, injections of saline, 4, 8, and $16 \mathrm{mg} / \mathrm{kg}$ of the competitive NMDA antagonist CPP ( \pm -3-2-carboxypiperazine-4-yl)-propyl-1-phosphonic acid were administered in a Latin-square design. Choice accuracy on both the place task and the cue task was significantly impaired by 8 and $16 \mathrm{mg} / \mathrm{kg}$ of CPP, whereas running times were significantly slowed only with $16 \mathrm{mg} / \mathrm{kg}$. This pattern of results is different from the selective impairment on the place task found following disruptive lesions of and kindling within the hippocampus. These findings suggest that care should be taken in attributing changes in behavior following injections of NMDA antagonists to selective effects on the hippocampus.
\end{abstract}

Antagonists of the NMDA receptor have been shown to block the formation of hippocampal long-term potentiation while leaving normal fast excitatory synaptic transmission intact (Abraham \& Mason, 1988; Harris, Ganong, Monaghan, Watkins, \& Cotman, 1986; Morris, 1989; Morris, Anderson, Lynch, \& Baudry, 1986; Morris, Halliwell, \& Bowery, 1989). Although NMDA receptors are present in a number of brain structures, including septum, amygdala, cerebellum, and the spinal cord, the density of these receptors is highest within the CA1 cell field of the hippocampus (Monaghan \& Cotman, 1985).

Several investigators have examined the effects of competitive and noncompetitive NMDA antagonists on tasks that are thought to require the integrity of the hippocampus for normal performance. Thus, NMDA antagonists have been reported to produce deficits on passive avoidance tasks (Benvenga \& Spaulding, 1988; Danysz, Wroblewski, $\&$ Costa, 1988), taste potentiation of odor aversion (Robinson, Crooks, Shinkman, \& Gallagher, 1989), delayed conditional discrimination (Tan, Kirk, Abraham, \& McNaughton, 1989), operant DRL (Tonkiss, Morris, \& Rawlins, 1988), the radial maze (Butelman, 1989; Danysz et al., 1988; Shapiro \& Caramanos, 1990; Ward, Mason, $\&$ Abraham, 1990) and the Morris swimming task (Morris, 1989; Morris et al., 1986; Morris et al., 1989; Robinson et al., 1989; Wishaw \& Auer, 1989). The above experiments using the radial maze and swimming task are in general agreement in showing that administration of small amounts of the noncompetitive NMDA antagonist MK-

This research was supported by NSF Grant BNS 88-09208 to L.E.J. and a R. E. Lee Research Grant to G.L.L. Correspondence should be addressed to L. E. Jarrard, Department of Psychology. Washington and Lee University, Lexington, VA 24450.
801 and the competitive antagonist AP5 disrupt the acquisition of new spatial information, but not performance of well-learned spatial tasks.

In an attempt to obtain a better understanding of how the hippocampus is involved in learning and memory, we have carried out a series of experiments designed to study the utilization of spatial versus nonspatial information in rats with hippocampal lesions. We used a radial maze together with a within-subjects design and a procedure that permits determining two types of learning (place and cue) and two memory functions (working and reference memory). In the place task, the animal learns to choose four out of eight similar arms, with all arms remaining in the same spatial location from trial to trial. In the cue task, textured arm inserts in the eight arms are moved in a random order from trial to trial, and the rat is rewarded for choosing the same four cues. Working memory (WM) refers to information that is pertinent for only a single trial (and is operationally defined as errors that involve repeating choices of arms within a trial). Reference memory $(\mathrm{RM})$ involves remembering information across trials (and is reflected in choices of arms and cues that are never baited; see Honig, 1978). In terms of difficulty, the place and cue tasks are generally similar, although rats do make slightly more errors in learning the cue task (Jarrard, 1986).

Using the above place and cue tasks, Jarrard (1986) found that aspiration lesions of the hippocampus result in impairments in both acquisition and retention of the place task but not the cue task. Furthermore, the selective impairment on the place task was characterized by increases in both RM and WM errors. More selective removal of the hippocampus with injections of ibotenic acid resulted in impaired acquisition of the place task (Leu, Johnson, \& Jarrard, 1987); however, if the tasks were 
learned before the hippocampus was removed, performance on the place task was only temporarily impaired (Jarrard, 1986). Further evidence for a selective involvement of the hippocampus in handling spatial information was found in an experiment that involved kindling from the hippocampus (Jarrard \& Walczak, 1986). Following training on the place and cue radial maze tasks, the rats were tested while undergoing daily kindling trials. As kindling developed, the rats became increasingly impaired on the place, but not the cue, task. The pattern of results obtained in these experiments indicates that disruption of the hippocampus results in a selective impairment on the place, but not the cue, radial maze task.

Due to the selective impairment on the place task that was found when hippocampal function was disrupted, and the possibility that the hippocampus would be affected by injections of NMDA antagonists, we examined, in the present research, the effects of various doses of CPP, a competitive NMDA antagonist (Harris et al., 1986; Lehmann et al., 1987), on performance of the place and cue tasks described above.

\section{METHOD}

\section{Subjects}

Twenty experimentally naive Sprague-Dawley-derived male rats, weighing between 240 and $290 \mathrm{~g}$, were the subjects. The animals were maintained at $85 \%$ of their free-feeding weight, with water available at all times. Each rat was housed individually in a temperature- and humidity-controlled room where illumination was set on a 12:12-h light:dark cycle (lights on at $0600 \mathrm{~h}$ ).

\section{Apparatus}

The wooden radial maze had an octagonal center platform with eight arms (see Jarrard, Okaichi, Steward, \& Goldschmidt, 1984). Each arm was fitted with Plexiglas sides and a Plexiglas tray at the distal end in which a shallow hole was drilled to serve as a container for the two drops of $23 \%$ sucrose reinforcement. The maze was located in a well-illuminated room containing numerous extramaze cues (window, door, rack of cages, table, counters, cupboard, fluorescent light, and experimenter).

For testing on the cue task, a single $100-\mathrm{W}$ incandescent bulb in a lamp shade was used for illumination. This light was suspended $50 \mathrm{~cm}$ above the center of the maze platform. The cues consisted of eight plywood inserts that fit into each arm. One of a variety of materials (cloth, screen, ceiling tile, chicken wire, carpet, sandpaper, sheet aluminum, or bare wood) was attached to each insert.

\section{Procedure}

After several days of handling and deprivation, each animal was trained on both the place task and the cue task. In the place task, the rat was rewarded for visiting the same four of eight arms on all trials. The "correct" four arms were different for each animal. Likewise, for the cue task, an animal was rewarded for choosing the same four (out of eight) cues on all trials. Location of the cue inserts was arranged in a pseudorandom order from trial to trial. The "correct"' set of cues was different for each animal. For a trial, the rat was placed on the center platform and remained on the maze until the four baited arms (or cues) had been chosen, until 16 arms were visited, or until the rat had been on the maze for $5 \mathrm{~min}$. The animals were given two trials on both tasks each day. Within a day, task order was alternated (place, cue, place, cue); on the following day, the reverse order was employed. The intertrial interval was approximately $10 \mathrm{~min}$. The total running time for each trial and the arms selected for each trial were recorded. For testing purposes, the rats were divided into five squads of four animals each. Training was conducted 5 days each week for 7 weeks prior to drug testing.

The 4 drug-testing days were each separated by 6 days without drug administration ( 2 days of training, 2 rest days, and 2 additional training days). On test days, the animal received an intraperitoneal injection of saline, 4,8 , or $16 \mathrm{mg} / \mathrm{kg} \mathrm{CPP} 45 \mathrm{~min}$ prior to being tested. The CPP was dissolved in physiological saline; all animals received injections of the same volume-to-weight ratio at each dose. The order in which the doses were injected was counterbalanced according to a Latin-square design. The doses of CPP that were employed and the time between injection and the beginning of testing were determined in a pilot experiment.

\section{RESULTS}

The percent correct of the first four choices are shown in Figure 1. On this measure, it is evident that choice accuracy decreased as doses of CPP increased. An ANOVA revealed a significant main effect of injection $[F(3,57)=$ $35.40, p<.01]$. Subsequent analysis with the NewmanKeuls test showed that performance was more affected by the $8-\mathrm{mg} / \mathrm{kg}$ dose than with the $4-\mathrm{mg} / \mathrm{kg}$ dose or the saline $(p<.01)$. In addition, choice accuracy was more affected at $16-\mathrm{mg} / \mathrm{kg}$ dose than at any of the other doses $(p<.01)$. Performance on the place and cue tasks did not differ $[F(1,19)=1.61, p=.22]$. Neither place nor cue was differentially affected by the dose of CPP $[F(3,57)=1.63, p=.19]$.

The above measure did not allow a comparison of WM and RM errors. For this comparison, an ANOVA of raw error scores was carried out. This analysis indicated that

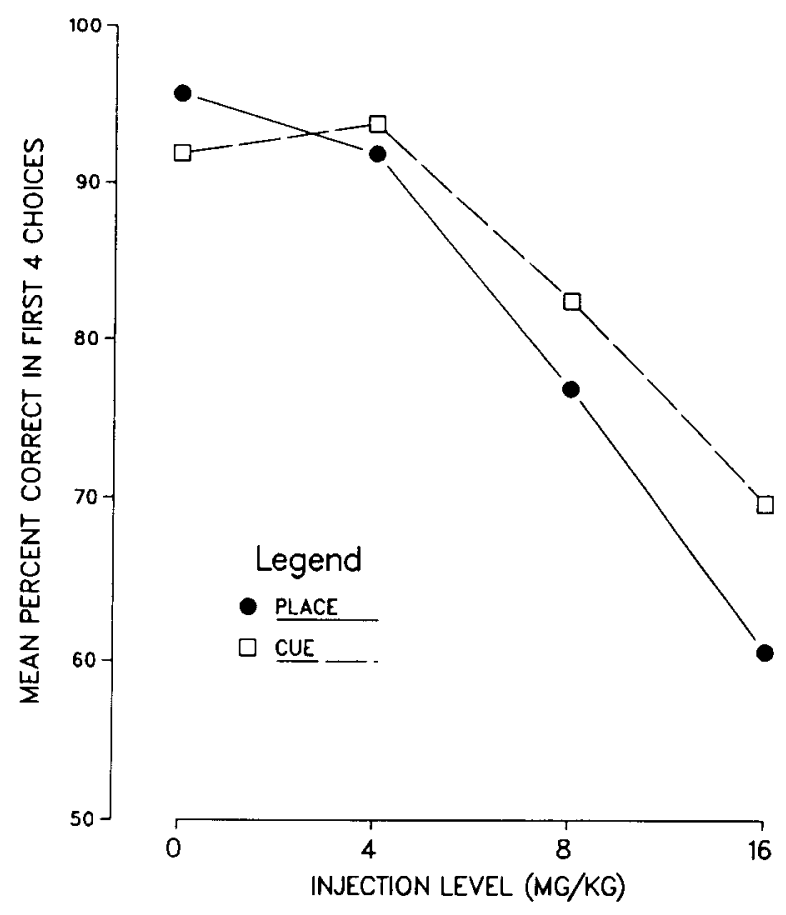

Figure 1. Mean percent correct responses in the first four choices as a function of dose of CPP. 


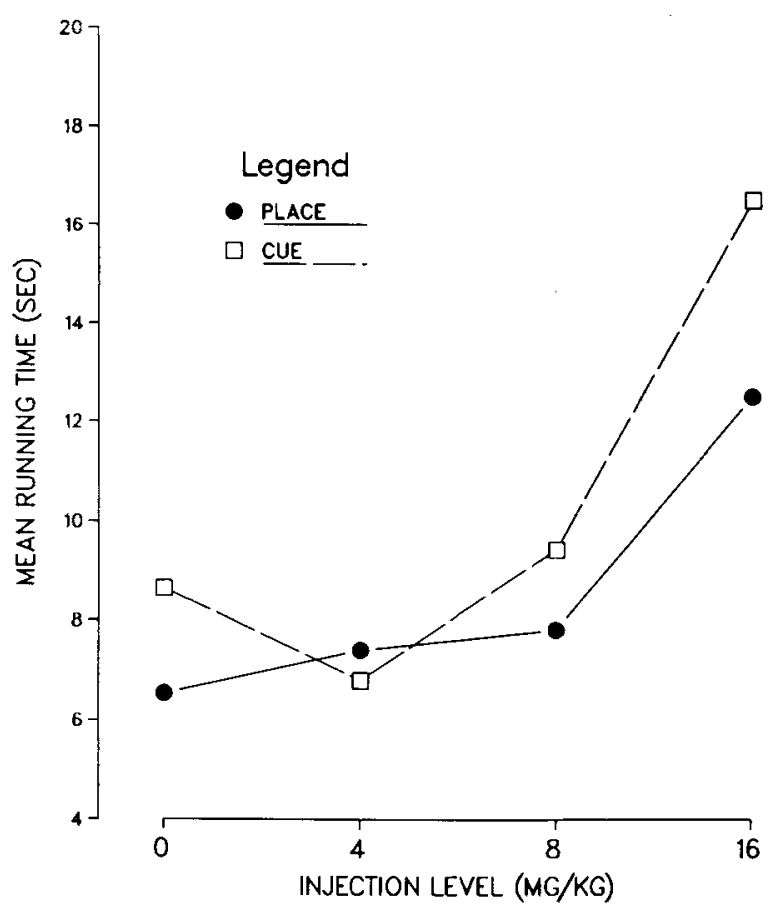

Figure 2. Mean running time per choice as a function of dose of CPP.

CPP did not produce an increase in WM errors, relative to $\mathrm{RM}$ errors $[F(3,57)=2.62, p=.06]$.

Figure 2 shows the average length of time taken by the animals to visit an arm (e.g., total running time divided by number of arms visited). An ANOVA confirmed that, overall, the animals were slower on the cue task than on the place task $[F(1,19)=15.63, p<.01]$, and that running time was affected by the different doses of CPP $[F(3,57)=28.54, p<.01]$. A subsequent NewmanKeuls test revealed that the average running time at the $16-\mathrm{mg} / \mathrm{kg}$ dose was significantly longer than at any of the other three doses $(p<.01)$, whereas the average time per arm at the $8-\mathrm{mg} / \mathrm{kg}$ dose did not differ significantly from that at the 0 - and $4-\mathrm{mg} / \mathrm{kg}$ doses $(p>.10)$. The running times on the two tasks were differentially affected by the various doses of CPP $[F(3,57)=3.42, p<.05]$. Further analysis revealed that the rats ran significantly more slowly on the cue task than they ran on the place task at 0,8 , and $16 \mathrm{mg} / \mathrm{kg}$ of CPP $(p<.05)$; they ran at the same rate on both tasks at the $4-\mathrm{mg} / \mathrm{kg}$ dose. The animals were observed to consume the sucrose reinforcements even at the highest dose of CPP.

Choice accuracy and running times for the day following drug administration were also analyzed. An ANOVA confirmed that CPP did not have an effect on either choice accuracy $[F(3,57)=1.22, p=.31]$ or running time $(F<1.0) 24 \mathrm{~h}$ after the injection. There was no significant interaction of task $\times$ injection for choice accuracy or average time per arm $(F \mathrm{~s}<1.0)$. Thus, the effects of CPP were not evident after $24 \mathrm{~h}$.

\section{DISCUSSION}

A point of concern in behavioral research that involves the administration of drugs, and a concern that is especially relevant in research where systemic injections of NMDA antagonists are made, is the possibility that changes in performance may be due to nonspecific effects on sensory, motor, and/or motivational processes (Keith \& Rudy, 1990; Morris, 1990). In this regard, it is interesting that, in the present research, accuracy of responding was found to be affected at a lower dose of CPP than was running time. Observation of the rats after the $8-\mathrm{mg} / \mathrm{kg}$ dose of CPP indicated that they not only ran the maze as quickly as they did following the saline injection but also readily consumed the sucrose reinforcement. Thus, the poorer performance at the $8-\mathrm{mg} / \mathrm{kg}$ dose without an accompanying increase in response time suggests that the decreased accuracy cannot be attributed to motor effects or to decreases in motivation. Other nonspecific sensory and/or perceptual impairments cannot be ruled out.

The similar impairment on both the place task and the cue task found with increasing doses of CPP is different from the selective effect on the place task that is found following aspiration of the hippocampus (Jarrard, 1986) and kindling from the hippocampus and amygdala (Jarrard \& Walczak, 1986). The more general effect with CPP would seem to indicate that the impairments found with injections of the NMDA antagonist cannot be attributed to a selective effect of the drug on the hippocampus. Monaghan and Cotman (1985) have shown that there are a number of structures in addition to hippocampus that have a relatively large number of NMDA receptors, and one could reasonably assume that an intraperitoneal injection would allow the drug to have access to these structures as well as the hippocampus. Thus, even though the CA1 cells in the hippocampus have one of the highest densities of NMDA receptors in the brain, it seems unlikely that $\mathrm{CPP}$ would selectively affect the hippocampus without also affecting the functioning of other structures.

Most behavioral studies using NMDA antagonists have been concerned with the acquisition of new information. Learning, rather than retention, has been emphasized primarily because NMDA antagonists presumably block the induction of NMDA-dependent long-term potentiation without interfering with synaptic transmission (Coan, Saywood, \& Collingridge, 1987; Morris et al., 1986). Thus, there is a basis for predicting that performance of some components of the well-learned spatial and cue tasks used in the present research should be minimally affected by CPP. Specifically, the animals had already learned which four arms (and four cues) were baited over trials and which were not baited; one might expect that RM would not be affected. On the other hand, if the hippocampus is especially affected by CPP, the rats should have difficulty remembering which arms (or cues) had already been visited on that trial (e.g., the WM component). The data clearly show that both RM and WM were affected, and 
were affected to a similar extent. Similar RM and WM CPP-induced impairments on well-learned spatial radialarm maze tasks have been reported (Ward et al., 1990). Given that performance on both the place task and the cue task was equally affected (whereas hippocampal disruption selectively affects only place performance), the pattern of results clearly suggests that other brain regions and/or processes must be affected by intraperitoneal injections of CPP.

Our finding that CPP affected performance of the spatial and cue tasks at a dose level that did not affect motor performance fails to agree with results recently reported by Shapiro and Caramanos (1990). These investigators found that acquisition of a radial maze task was impaired by MK-801 but that similar injections after the task had been learned had no effect; larger doses caused mild ataxia together with impairments in WM and RM. Given that both drugs are NMDA antagonists, the reasons for the conflicting results obtained with CPP and MK-801 are not clear. However, the different behavioral results may be due to a different mechanism of action for CPP, a competitive antagonist, and MK-801, a noncompetitive antagonist.

In summary, the major findings of the present research are (1) unlike the selective impairment on the place task that results following hippocampal disruption, a general impairment on both the place task and the cue task was found with increasing doses of CPP, and (2) the impairments cannot be attributed to changes in motor or motivational processes, since accuracy of performance was affected by an amount of CPP that did not slow running times. This pattern of results suggests that care should be taken in attributing changes in behavior following intraperitoneal injections of NMDA antagonists to selective effects on the hippocampus.

\section{REFERENCES}

AbrahaM, W. C., \& MASON, S. E. (1988). Effects of the NMDA receptor/ channel antagonists CPP and MK-801 on hippocampal field potentials and long-term potentiation in anesthetized rats. Brain Research, 462, 40-46.

Benvenga, M. J., \& Spaulding, T. C. (1988). Amnesic effect of the novel anticonvulsant MK-801. Pharmacology, Biochemistry, \& Behavior, 30, 205-208.

Butelman, E. R. (1989). A novel NMDA antagonist, MK-801, impairs performance in a hippocampal-dependent spatial learning task. Pharmacology, Biochemistry, \& Behavior, 34, 13-16.

Coan, E. J., Saywood, W., \& Collingridge, G. L. (1987). MK-801 blocks NMDA receptor-mediated synaptic transmission and long-term potentiation in rat hippocampal slices. Neuroscience Letters, 80 , 111-114.

DanYsz, W., WroblewsKi, J. T., \& Costa, E. (1988). Learning impairment in rats by $\mathrm{N}$-methyl-D-aspartate receptor antagonists. Neuropharmacology, 27, 653-656.

Harris, E. W., Ganong, A. H., Monaghan, D. T., Watkins, J. C., \& Cotman, C. W. (1986). Action of 3-(( \pm$)$-2-carboxypiperazin-4yl)-propyl-1-phosphonic acid (CPP): A new and highly potent antagonist of N-methyl-D-aspartate receptors in the hippocampus. Brain Research, 382, 174-177.
HoniG, W. K. (1978). Studies of working memory in the pigeon. In S. H. Honig, J. Fowler, \& W. K. Honig (Eds.), Cognitive processes in nonhuman primates (pp. 211-248). Hillsdale, NJ: Erlbaum.

JARRARD, L. E. (1986). Selective hippocampal lesions and behavior: Implications for current research and theorizing. In R. L. Isaacson \& K. H. Pribram (Eds.), The hippocampus (Vol. 4, pp. 93-126). New York: Plenum Press.

Jarrard, L. E., Okaichi, H., Steward, O., \& Goldschmidt, R. B. (1984). On the role of hippocampal connections in the performance of place and cue tasks: Comparisons with damage to hippocampus. Behavioral Neuroscience, 98, 946-954.

JARRARD, L. E., \& WALCZAK, D. D. (1986). Effects of hippocampal kindling on performance of a complex place and cue memory task in the rat. Society for Neuroscience Abstracts, 12, 743.

KEITH, J. R., \& RUDY, J. W. (1990). Why NMDA-receptor-dependent long-term potentiation may not be a mechanism of learning and memory: Reappraisal of the NMDA-receptor blockade strategy. Psychobiology, 18, 251-257.

Lemmann, J., Schneider, J., McPherson, S., Murphy, D. E., Bernard, P., Tsai, C., Bennett, D. A., Pastor, G., Steel, D. J., Boehm, C., Cheney, D. L., Liebman, J. M., Williams, M., \& WooD, P. L. (1987). CPP, a selective N-methyl-D-aspartate (NMDA)type receptor antagonist: Characterization in vitro and in vivo. Journal of Pharmacology \& Experimental Therapeutics, 240, 737-746.

LEU, J. R., JohnSon, L. S., \& JARRARD, L. E. (1987). Effects of ibotenic acid lesions of the hippocampus on acquisition of a radial maze memory task. Society for Neuroscience Abstracts, 13, 646.

Monaghan, D. T., Cotman, C. W. (1985). Distribution of N-methylD-aspartate-sensitive $\mathrm{L}[3 \mathrm{H}]$ glutamate-binding sites in rat brain. Joumal of Neuroscience, 5, 2909-2919.

MorRIs, R. G. M. (1989). Synaptic plasticity and learning: Selective impairment of learning in rats and blockade of long-term potentiation in vivo by the $\mathrm{N}$-methyl-D-aspartate receptor antagonist AP5. Joumal of Neuroscience, 9, 3040-3057.

Morris, R. G. M. (1990). It's heads they win, tails I lose! Psychobiology, 18, 261-266.

Morris, R. G. M., Anderson, E., Lynch, G. S., \& Baudry, M. (1986). Selective impairment of learning and blockade of long-term potentiation by an $\mathrm{N}$-methyl-D-aspartate receptor antagonist, AP5. Nature, 319, 774-776.

Morris, R. G. M., Halliwell, R. F., Bowery, N. (1989). Synaptic plasticity and learning: II. Do different kinds of plasticity underlie different kinds of learning? Neuropsychology, 27, 41-59.

Robinson, G. S., JR., Crooks, G. B., JR., Shinkman, P. G., \& Gallagher, M. (1989). Behavioral effects of MK-801 mimic deficits associated with hippocampal damage. Psychobiology, 17, 156-164.

Shapiro, M. L., \& Caramanos, Z. (1990). NMDA antagonist MK801 impairs acquisition but not performance of spatial working and reference memory. Psychobiology, 18, 231-243.

Tan, S., Kirk, R. C., Abraham, W. C., McNaughton, N. (1989). Effects of the NMDA antagonists CPP and MK-801 on delayed conditional discrimination. Psychopharmacology, 98, 556-560.

Tonkiss, J., Morris, R. G. M., \& Rawlins, J. N. P. (1988). Intraventricular infusion of the NMDA antagonist AP5 impairs performance on a non-spatial operant DRL task in the rat. Experimental Brain Research, 73, 181-188.

Ward, L., Mason, S. E., \& Abraham, W. C. (1990). Effects of the NMDA antagonists CPP and MK-801 on radial arm maze performance in rats. Pharmacology, Biochemistry, \& Behavior, 35, 785-790.

Whishaw, I. Q., \& AUER, R. N. (1989). Immediate and long-lasting effects of MK-801 on motor activity, spatial navigation in a swimming pool and EEG in the rat. Psychopharmacology, 98, 500-507.

(Manuscript received October 11, 1990; revision accepted for publication April 8, 1991.) 